\title{
Patient perspective: life in the melanoma patient community and the emergence of the melanoma patient conference
}

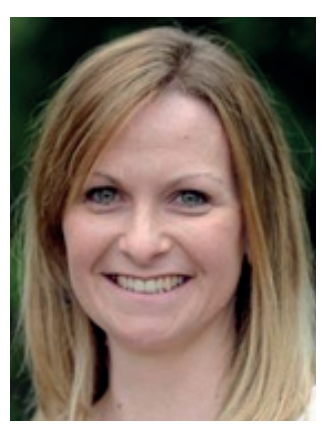

Imogen Cheese speaks to Sebastian Dennis-Beron, Commissioning Editor: Imogen was diagnosed with melanoma in June 2013 (currently stage 2C no evidence of disease monitored under Professor Mark Middleton at Oxford) and has since created and writes a website blog (www.melanomarollercoaster.co.uk) as well as founded the melanoma patient conference in 2015. As an impartial event, the patient conference brings together all stakeholders involved in melanoma diagnosis, treatment and care; this includes clinicians, charities and crucially, people living and dying with melanoma. This means the only end goal for the conference are the ongoing needs of patients and families. Imogen's blog has a readership of over 2000 people - many of whom are melanoma patients in the UK. She is prolific in her contact with these patients on social media and as a result of her blog, she has been asked to represent melanoma patients in the UK as their advocacy representative at numerous conferences and events across Europe (including ECC2015 and the MPNE annual events in Brussels). Patients reach out to Imogen on a daily basis asking for support and seeking a means to improve their knowledge and obtain access to better care and information on the latest drugs and trials in the UK.

She is a member of the Melanoma Patient Network Europe and speaks daily to over 300 patients on an online support group on social media. Imogen was invited by the British Skin Foundation to support them in establishing a skin cancer specific arm of their charity called ITTakes7 and has worked directly with Melanoma UK on various projects for patient interaction and information gathering. She is connected with Cancer Research UK as a patient representative with the ECMC network and involved with the Oxford hospitals as an advisor for their public engagement and planning. Imogen can be found on twitter at @MelanomaBlog.

Accepted for publication: 10 April 2017; Published online: 19 May 2017

Could you tell our audience a little about your life up to this point?

I live in Gloucestershire with my husband and two children who are 11 and 9.

I was 6 months old when my family emigrated to East Africa where we lived until I was 10 when we moved to Cyprus for a few years.
While I would not change any aspect of my wonderful childhood, there is little doubt that the intense sun exposure in my formative years could well be a significant factor in me having melanoma.

I am naturally pale in skin tone, with freckles and lots of moles and have red hair in the family so I would have been

\section{KEYWORDS}

- conferences • melanoma • patient advocacy $\bullet$ patient perspective - quality of life

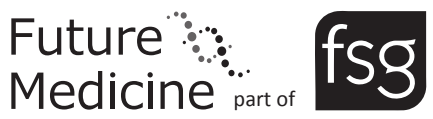


vulnerable anyway.

If nothing else, melanoma has made me aware of genetics and I am extremely vigilant and protective of my children's skin.

\section{Q What was your reaction to your melanoma} diagnosis in 2013?

I was diagnosed on Tuesday, 11 June 2013 at $11.15 \mathrm{am}$.

It makes me sad just thinking about that day. It will be burned into my memory forever. Not just because of being told that I had melanoma, but also the traumatic nature of the day. After I was informed, I also had a wide local excision the procedure to remove the surrounding tissue and hopefully obtain clean margins.

That afternoon just $2 \mathrm{~h}$ after I had been advised that I had melanoma, surgery was performed under local anesthetic. I can recall this completely. The smell of the blood vessels being cauterized, the sudden feeling of helplessness and uncertainty. A fear and anxiety that had never been present in my life before were now suddenly predominant.

\section{Q Can you give us an outline of your current} treatment course?

I am at stage IIC; until my melanoma progresses there is nothing that can be done.

I did attempt to get into a clinical trial immediately after I was diagnosed, however during the baseline tests, a secondary and partially connected cancer was discovered, which ruled out my taking part in the trial.

I changed my lifestyle and diet immediately and I truly believe that this has played a part in my being healthy and no evidence of disease since then.

I am not alone in having a second issue discovered immediately after a melanoma diagnosis. Research is ongoing into why this happens, but despite my disappointment at not getting onto the trial, I am thankful the tests uncovered an issue that wouldn't have been spotted until it was too late otherwise.

\section{Q What do you feel are some of the best} aspects of your care? Are there aspects you feel could be improved on?

I transferred my care from one trust to another, initially just because I wanted to get access to a clinical trial and the trust I lived within did not offer it or any other trials into melanoma. I did however ask to remain under the care of Mark
Middleton and Oliver Cassell at the Churchill Hospital (Oxford University, Oxford, UK).

They are experts both in melanoma and skin cancer in general, but also the team at Oxford places a much higher level of importance upon the patient's wellbeing and support them throughout their diagnosis and treatment.

I trust my medical team now and I feel that if I needed help I would be able to reach out immediately.

There are, as I have become acutely aware of since then, great disparities of care across the UK. This is an extension of the postcode lottery idea that was so prevalent 10 years ago. It is not just about access to drugs, because now patients are more aware of the importance of traveling to the best centers to get access to trials and experts in their field.

The disparities now link more to the finances and the value that is placed within the hospitals across the country on going 'above and beyond' the statistics and figures they have to meet. Things like training for their staff, frequency of scans and supporting tests, information and literature for patients, support services and even the amount of time patients get to spend at an appointment.

It all adds up to whether the patient is seen as just a number or whether they get to remain a person after being diagnosed with cancer.

Q Soon after your diagnosis, you began a personal blog detailing your experience as a patient, which has sparked a dialogue between you \& your readers. How important is communication between patients \& the sharing of experiences?

I started my blog originally to leave a record for my children who were very young and the blog grew from there.

Soon I was being contacted by melanoma patients from all over the UK (and further afield) that had also experienced great sadness and unnecessary stress in the process of being diagnosed, which made me very angry.

There is no reason for patients to feel alone and isolated. Worse still is that much of the time the teams that care for these patients are not aware that the patient feels this way - or they feel powerless to help and provide the right type of support.

People do not learn and grow through anger and pointing fingers at failure; instead we should highlight where it is done right and share that 
with everyone so that in time the standards and levels of support are brought up and unified.

Communication is the key to this process, not just through patients' learning from medical professionals, but vice versa. We all are a part of this experience and we can all benefit from what each other brings to the table.

Q Building on this, in 2016 you initiated the UK's first melanoma patient conference that brought together clinicians, advocates \& patients. What was the principal aim of this conference?

When I decided to create the melanoma patient conference [1] it was because there was this gap in the arena. There was not a platform or place where patients could go to learn and also to network at the same time.

There were melanoma conferences or cancer events that touched on melanoma, but nothing specific, with patients often feeling unwelcomed or not even able to attend.

I wanted to create an annual event that would be attended by patients (and carers), by the medical professionals that treat them at all levels within their care and also by pharmaceutical companies and charities - basically every stakeholder involved.

The idea is to have learning and teaching sessions so that key up to date information is shared to promote growth and empower the patients with knowledge. Simultaneously, there is an opportunity to network and meet others who are experiencing the same things. We look at and discuss all the key issues that patients face.

We look at how to raise awareness, improve early diagnosis, share information about clinical trials and improve the general quality of lives as patients.

The first conference in 2016 was a huge eye opener for me; not only was it the first event I had ever organized, but it showed that there was this enormous need and want for the conference to happen and it was not just the patients that felt this way - the medical professionals did too.

\section{Q What is the importance of meetings} such as the patient conference in making the patient's voice heard at various levels of healthcare, from primary care, to the pharmaceutical industry \& even legislature? Having a patient conference where the numbers that attend are so great shows that there is a real desire from the melanoma community to become more actively involved in our care and treatment.

There were 250 delegates in 2016 and as long as we get enough sponsorship this year we would ideally like to welcome 350 delegates to the 2017 event.

A conference like this needs to be informative, compassionate and of course professional. There is no point in bringing together everyone involved in melanoma for it to simply provide patients with an opportunity to complain or voice anger, frustrations and fear.

As a patient community, we need to understand that little can be done about what brought us to the table in the first place - but we can use our combined knowledge and strength to ensure that nobody ever has to experience it again; we can collaborate with others to ensure that greater value is placed upon not just how we are treated, but how we live with the diagnosis and how we can survive better, for longer.

We can use this platform to engage properly with the media, in an informed way, so that awareness of melanoma improves and early diagnosis becomes a greater national issue than it currently is.

In doing all of this, we show unity and we demonstrate to everyone that patients are now at the center of their care for the right reasons. After all we are more than just cancer and before becoming a patient we were 'somebody' - somebody that can bring something important to the conversation too.

\section{Q What else can be done to engage patients \& survivors into taking on an advocacy role such as you have?}

I think taking on a role to the extent I have done is quite unusual. The amount of time I dedicate to this conference and the time sacrifices I make as a volunteer advocate are not something that most patients or their families would be able to make. This is very much a labor of love for me.

I would encourage other patients and survivors to attend conferences, look at online courses to improve their knowledge and learning of the disease they face.

Once they understand the challenge, they face fully and have the right knowledge with which to discuss it eloquently, they can then look at what matters most to them within their disease area.

The charities involved in melanoma are always keen to include patients in their projects and are desperate for trustees and ambassadors.

Patients and their families often feel that 
the only way they can get involved and make a difference is by taking part in a sporting event or raising money. There are so many other things that they can do and they should have the confidence in reaching out and contacting the charities directly.

If they look at the charity websites, they can get a better idea of what they do, as each of the charities take slightly different approaches and targets.

Alternatively, all the charities involved with melanoma will be at the melanoma patient conference, so they can always meet them there.

All of the leading hospitals in the country are also keen to welcome patient ambassadors, to help guide their initiatives, to engage with other patients and to drive ongoing improvements at their center. I would definitely encourage them to reach out to their hospitals patient engagement teams. Being involved can be done from home, in your local area or nationally. It isn't an all or nothing situation - all of our voices count.

\section{Q How would you like to see melanoma} patient care evolve over the coming years? I would like melanoma patients to be consulted more at every level of their care.

I would like to see more money being invested in GP and dermatology training. There are still too many patients that are being misdiagnosed who are not getting the melanoma removed quickly enough.

I would like to see a national campaign of some kind to start to change the general population's attitude to sun protection and skincare.

$\mathrm{UV}$ is cumulative - damage can occur from just one incidence of severe burning or prolonged exposure to the sun. People still use sunbeds too which I find astounding. I have even seen promotions and discounts for sunbed use offered to university-aged children.

If we place greater importance of not getting sun damage and looking after our children's skin, then gradually the incidences of melanoma diagnoses, which are currently still increasing exponentially, will start to decline.

Also, I would like every patient to be informed fully about clinical trials, psychosocial support that is available and end of life care. Sadly, these are areas where so little support is currently offered nationally. There should be just as much care given to quality of living as there is to quality of dying.

Melanoma can be brutally cruel and the goal is to take some of that pain away both for the patient and the family they may eventually leave behind.

\section{Q What is next for you in your work as an advocate?}

I will continue to organize the melanoma patient conference every year. It is a huge undertaking in itself and we are always looking for sponsorship and financial support to bring it to fruition.

I believe that more can be done to unify standard of care, but also there are some great initiatives that are already happening in hospitals up and down the UK, that others are not aware of and we could all benefit from learning about.

My advocacy is about improving melanoma care and treatment the right way - positively.

I am an optimistic person and I believe that if you can show others that you are not scared to step out of your comfort zone to help others and make a difference, then other patients and medical professionals will follow suit.

\section{Closing statement}

The melanoma patient conference is, other than my children, the thing I am most proud of.

It matters both to me as a patient and to every single person that comes to attend it.

The event provides and displays hope; there currently is not a cure for melanoma so until the wonderful advances of melanoma research and drug treatments can provide a patient with more than just time, reduced effects and burdens from treatments we should focus on what we can change.

Together the melanoma patient community and all those involved with melanoma treatment and care can stand together. Melanoma is a frightening disease and my dream is to ensure that any newly diagnosed patient knows they are not alone.

\section{Disclaimer}

The opinions expressed in this interview are those of the interviewee and do not necessarily reflect the views of Future Medicine Ltd, Churchill Hospital or the clinicians or any other institutions mentioned in the interview.

Financial \& competing interests disclosure The interviewee has no relevant affliations or financial involvement with any organization or entity with a financial interest in or financial conflict with the subject matter or materials discussed in the manuscript. This includes employment, consultancies, honoraria, stock ownership or options, expert testimony, grants or patents received or pending, or royalties. 
Life in the melanoma patient community \& the emergence of the melanoma patient conference INTERVIEW

No writing assistance was utilized in the production of this manuscript.

\section{Reference}

1 Melanoma Patient Conference.

www.melanomapatientconference.co.uk 